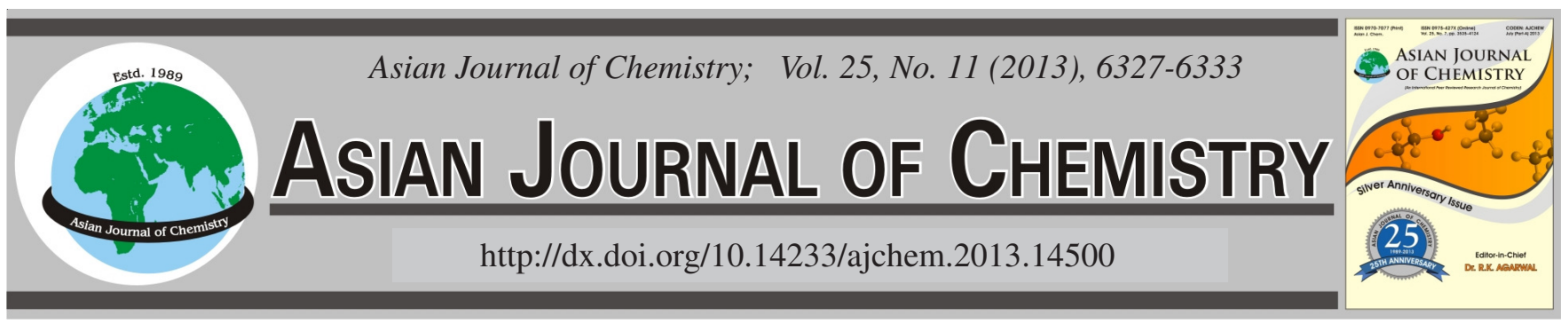

\title{
Synthesis and Characterization of Antimicrobial Metal Based Polymeric Ligand Derived from 4,4'-Methylene-bis(furfuraldehyde)
}

\author{
M.A. Mughal ${ }^{1}$, Akhtar Mughal $^{2}$, G. Zuhra Memon ${ }^{1, *}$ and Mohammad Y. Khuhawar ${ }^{1}$
}

${ }^{1}$ Dr. M.A. Kazi Institute of Chemistry, University of Sindh, Jamshoro, Pakistan

${ }^{2}$ Institute of Physics, University of Sindh, Jamshoro, Pakistan

*Corresponding author: E-mail: zuhramemon_chem@yahoo.com; moina_virgo@ hotmail.com

(Received: 29 August 2012;

Accepted: 8 May 2013)

AJC-13465

\begin{abstract}
The present study examines synthesis of a new monomer, 4,4'-methylene-bis(furfuraldehyde), by a general method. The monomer was further condensed with a 1,3-propylenediamine in (1:1) molar ratio to yield a Schiff base polymer ligand poly $(4,4$ '-methylenebis(furfuraldehyde)-1,3-propylenediimine (PMBFPR). The monomer (MBF) was prepared by the reaction of furfuraldehyde with 1,3,5trioxane in the presence of acetic acid. The Schiff base polymer (PMBFPR) was found to react readily with $\mathrm{Cu}(\mathrm{II})$ acetate monohydrate and $\mathrm{Ni}(\mathrm{II})$ acetate, yielding polymer metal complexes (PMBFPRCu) and (PMBFPRNi) respectively. The monomer (MBF), the polymer (PMBFPR) and the polymetal chelates, (PMBFPRCu) and (PMBFPRNi) were characterized by elemental micro analysis, FT-IR, ${ }^{\mathrm{I}} \mathrm{H}$ NMR, ultraviolet visible spectrophotometry, thermal analysis and viscosity measurements. The newly synthesized polymer and polymer metal complexes were screened against various microorganisms. For antibacterial activity Shigella flexneri, Micrococcus flavus, Staphylococcus aureus, Bacillus Cirroflgellosus, Escherichia Coli and for antifungal activity Candida albicans, A. Niger, Aspergillus flavus, were investigated by using 'agar well diffusion method'.
\end{abstract}

Key Words: Antimicrobial, Schiff base polymers, Synthesis, Coordination, Viscosity studies, Thermal analysis.

\section{INTRODUCTION}

The interests in the preparation of new polymers with diverse properties are increasing. The Schiff base polymers containing main functional group with conjugated system of $-\mathrm{C}=\mathrm{C}-$ and $-\mathrm{C}=\mathrm{N}$ - are conveniently prepared by polycondensation of diamines with dicarbonyl compounds ${ }^{1-4}$ they are used as catenation ligands for a number of metal ions ${ }^{5-8}$.

A number of Schiff base polymers have been prepared and characterized by spectroscopic techniques ${ }^{9-13}$. They have thermal stability similar to polyamides and have been used as solid stationary phase in packed column gas chromatography ${ }^{14}$. Some of them have electro-physical properties including as semiconductors ${ }^{15-16}$. However, these polymers have poor solubility in organic solvents and have high melting point, which limits their processing ${ }^{17}$. A number of Schiff base complexes were strongly viewed and used as exemplary molecules for biological oxygen carrying systems ${ }^{18}$. The Schiff base polymers exhibit biological activities against yeast, bacteria and fungi ${ }^{19,20}$. The present work reports the preparation of new aldehydemethylene-bis(furfuraldehyde) by incorporating heteroaromatic furyl group and a Schiff base polymer by polycondensation of the dialdehyde/monomer with diamine. The synthesized compounds were characterized by spectroscopic techniques, thermal analysis and viscosities measurements. Apart from these the ligand and their polymer metal complexes were found to be active against various microorganisms, like Shigella flexneri, Micrococcus flavus, Staphylococcus aureus, Bacillus cirroflgellosus, as antibacterial agents and for antifungal activity A. Niger, Aspergillus flavus and Escherichia coli, were investigated, by using 'agar well diffusion method' and it was found that polymer metal complexes showed enhanced biological activity as compared to the parent ligand.

\section{EXPERIMENTAL}

Freshly distilled furfuraldehyde (E-Merck, Germany) was used. Glacial acetic acid (E-Merck, Germany), 1,3-propylenediamine, 1,3,5-trioxane, copper(II) acetate monohydrate $\left[\mathrm{Cu}\left(\mathrm{CH}_{3} \mathrm{COO}\right)_{2} \cdot \mathrm{H}_{2} \mathrm{O}\right]$ and nickel(II) acetate tetra hydrate $\left[\mathrm{Ni}\left(\mathrm{CH}_{3} \mathrm{COO}\right)_{2} \cdot 4 \mathrm{H}_{2} \mathrm{O}\right)$ (E-Merck, Germany), Petri plates, bacterial and fungal strains. Hot plates, solvents and other reagents were purified according to the standard procedure.

Synthesis of 4,4'-methylene-bis(furfuraldehyde): To a solution of $17.3 \mathrm{~mL}$ of furfuraldehyde in $12.5 \mathrm{~mL}$ of glacial acetic acid at $90-95^{\circ} \mathrm{C}$ was bubbled nitrogen gas and was added drop wise with magnetic stirring $1.75 \mathrm{~g}$ of trioxane dissolved 
in $0.62 \mathrm{~mL}$ of glacial acetic acid. The temperature was maintained for $24 \mathrm{~h}$ and stirring was continued for whole reaction period. The reaction mixture was then poured into $250 \mathrm{~mL}$ of ice water and allowed to stand overnight. The black shiny solid obtained was washed with diethyl ether and acetone and was recrystallized with ethyl alcohol. The product was dried at $60-70{ }^{\circ} \mathrm{C}$ for $7-8 \mathrm{~h}$. The product melted at $>300{ }^{\circ} \mathrm{C}$.

Preparation of Poly[4,4'-methylene-bis(furfuraldehyde)-1,3-propylenediimine] (PMBFPR): $0.1 \mathrm{~g}$ of MBF was added in $20 \mathrm{~mL}$ of dimethyl formamide (DMF) and mixture was refluxed till the compound dissolved completely. The hot solution was filtered and $0.04 \mathrm{~mL} \mathrm{1,3-propylenediamine,}$ dissolved in DMF ( $1 \mathrm{~mL})$ was added. The reaction mixture was refluxed with constant stirring for $24 \mathrm{~h}$. The mixture was concentrated to half the volume and $15 \mathrm{~mL}$ of ethanol was added. Dark brown precipitate was filtered and washed with diethyl ether. The product was dried at $60-70{ }^{\circ} \mathrm{C}$ for $7-8 \mathrm{~h}$ product indicated melting point at $>350^{\circ} \mathrm{C}$. (Fig. 1).

Synthesis of polymer metal complexes (PMBFPRCu), (PMBFPRNi): The polymer metal complexes were prepared in equimolar ratio $(1: 1)$ of ligand and metal salts by making the solution of poly[4,4'-methylene-bis(furfuraldehyde)-1,3diiminopropane], dissolved in $(0.5 \mathrm{~g})$ dimethyl formamide (20- $25 \mathrm{~mL}$ ). Into the mixture, was added solution of nickel(II) acetate $(0.5 \mathrm{~g})$ or copper(II) acetate $(0.4 \mathrm{~g})$, dissolved in tetrahydrofuran $(20 \mathrm{~mL})$ and $(1 \mathrm{~mL})$ acetic acid was added and refluxed for $15 \mathrm{~min}$. The mixture was allowed to cool at room temperature and was stirred continuously for 6 days, the precipitate formed were filtered and washed with water, ethanol, tetrahydrofuran and diethyl ether and dried overnight, at room temperature at $0.01 \mathrm{~mm}$ pressure. The colour of copper complexes was light brown and the colour of nickel complexes were dark brown. All the poly Schiff chelates decomposed above $355^{\circ} \mathrm{C}$ and showed poor solubility in most of the organic solvents.

The IR spectra were recorded on Nicolet Avatar 330 FTIR (Thermo Nicolet Electron Corporation, USA) with attenuated total reflectance (ATR) accessory (smart partner) within 4000$600 \mathrm{~cm}^{-1}$. The elemental analysis of carbon, hydrogen and nitrogen was carried out by HEJ Research Institute of Chemistry, University of Karachi, Pakistan. UV-VIS spectrophotometric studies were carried out in DMF on Lambda 35 double beam spectrophotometer. Quartz cells of $1 \mathrm{~cm}$ path length were used throughout the study, within 185-700 nm.

The ${ }^{1} \mathrm{H}$ NMR of the monomer and polymer was recorded on a Bruker ACF 300 NMR spectrometer using deuterated dimethylformamide (DMF) as solvent and tetramethylsilane (TMS) as an internal reference.

The solubility of ligands and polymer metal complexes was tested in different organic solvents at room temperature.

The thermal analysis was recorded on thermo gravimetric thermal analyzer pyris diamond TG/DTA (Perkin Elmer, Japan) from room temperature to $600{ }^{\circ} \mathrm{C}$ with a nitrogen flow rate of $5 \mathrm{~mL} / \mathrm{min} .2 \mathrm{mg}$ Samples were placed in platinum crucible and recorded against alumina as reference with a heating rate $20^{\circ} \mathrm{C} / \mathrm{min}$.

The viscosity measurements of the monomer (MBF), polymer (PMBFPR) and polymer metal complexes
(PMBFPRCu) and (PMBFPRNi) in DMF with 0.024-0.064 $\mathrm{g} / \mathrm{dl}$ were noted in a temperature range from $283-323 \mathrm{~K}$ with an interval of $10 \mathrm{~K}$ by using a suspended level viscometer (Technico ASTM 445). Each time $15 \mathrm{~mL}$ of solution was used and average flow time was obtained from at least three readings. The flow time of solvent was also noted. A Gallenkamp viscometer water bath was used to control the temperature. The reduced viscosity $\left(\eta_{\text {red }}\right)$ was calculated by dividing specific viscosity $\left(\eta_{\mathrm{sp}}\right)$ by concentration $(\mathrm{g} / \mathrm{dL})$. The intrinsic viscosity ( $\eta$ ) was calculated by plotting $\eta_{\text {red }}$ against concentration and extrapolating to zero concentration. The thermodynamic parameters of the solution were determined from temperature dependence of the viscosity. The activation energy $(\Delta G)$ was calculated from the equation.

$$
\Delta \mathrm{G}=2.303 \mathrm{RT} \log .\left(\eta_{\mathrm{abs}} / 10^{-3}\right)
$$

where $\mathrm{R}$ is gas constant and $\mathrm{T}$ is absolute temperature.

A straight line was obtained by plotting $\log \eta_{\text {abs }}$ versus $1 / \mathrm{T}$. The values of activation heat of flow $\left(\Delta \mathrm{H}_{\mathrm{v}}\right)$ were calculated from the slope (slope XR). The entropy of activation of viscous flow $\left(\Delta \mathrm{S}_{\mathrm{v}}\right)$ was calculated from equation.

$$
\Delta \mathrm{G}_{\mathrm{v}}=\Delta \mathrm{H}_{\mathrm{v}}-\mathrm{T} \Delta \mathrm{S}_{\mathrm{v}}
$$

Antimicrobial activities of the investigated polymer and polymer metal complexes were determined by consuming an adapted agar well diffusion method.

\section{RESULTS AND DISCUSSION}

Elemental microanalysis: The results of elemental microanalysis for monomer ligands and poly metal chelates were closely correlated to the expected values (Table-1) and supported the formation.

TABLE-1

ANALYTICAL AND PHYSICAL DATA OF MONOMER, LIGAND AND POLYMER METAL COMPLEX

\begin{tabular}{lc|ccc}
\hline Compound & Yield & \multicolumn{3}{|c}{ Calculated (found) (\%) } \\
\cline { 3 - 5 } & $(\%)$ & $\mathrm{C}$ & $\mathrm{H}$ & $\mathrm{N}$ \\
\hline MBF & 86 & $64.7(63.39)$ & $4.36(4.35)$ & $-(-)$ \\
PMBFPR & 77 & $62.93(62.80)$ & $4.92(5.16)$ & $9.78(8.99)$ \\
PMBFPRCu & 82 & $54.98(54.80)$ & $4.61(3.65)$ & $9.16(8.99)$ \\
PMBFPRNi & 84 & $55.87(55.80)$ & $4.68(4.59)$ & $9.30(9.20)$ \\
\hline
\end{tabular}

Synthetic process: A new monomer (MBF) was synthesized following general procedure for the preparation of 5,5'methylene-bis(salicylaldehyde) and 5,5'-methylene-bis(2hydroxyacetophenone $)^{8,9,17}$. The addition of sulphuric acid to reaction medium was omitted. The reaction progressed smoothly and a dark shiny blackish product was isolated, which corresponded to the monomer (MBF). The monomer and diamine in (1:1) molar ratio were refluxed together as their solutions in DMF. At the end of the reaction the polymeric product was isolated. The Schiff base polymer (PMBFPR) was found to react readily with $\mathrm{Cu}$ (II) acetate monohydrate and $\mathrm{Ni}(\mathrm{II})$ acetate, yielding Polymer metal complexes (PMBFPRCu) and (PMBFPRNi) respectively (Fig. 1).

Vibrational spectra: The FT-IR spectra of monomer (MBF) indicated strong bands at $1690 \mathrm{~cm}^{-1}$ and $1700 \mathrm{~cm}^{-1}$ due to $v(\mathrm{C}=\mathrm{O})$ vibration. The similar peak in the ligand was found 


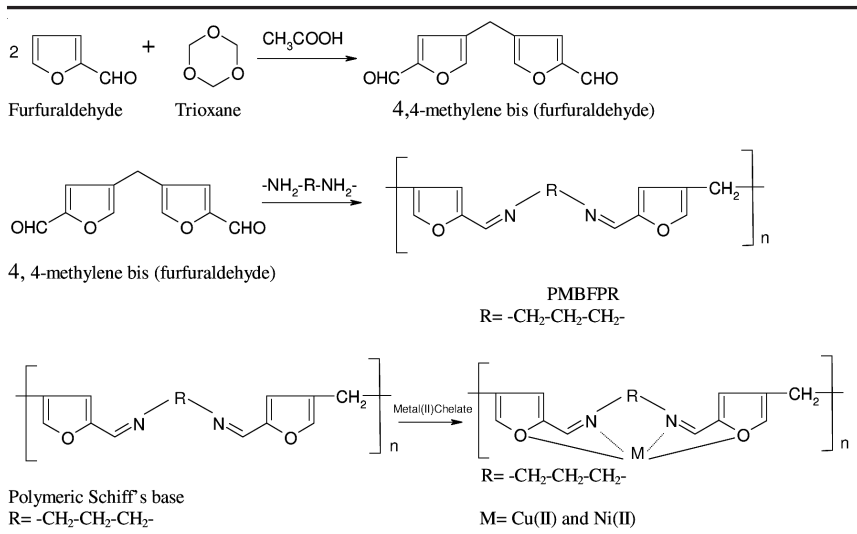

Fig. 1 .

to be weak or absent. IR absorption bands for the monomer, ligands and their complexes with conditional assignments are accessible in Fig. 2[a,b,c]. The ligand (PMBFPR) showed number of bands of varying intensities above $3000 \mathrm{~cm}^{-1}$ due to aromatic $v(\mathrm{C}-\mathrm{H})$ stretching and bands around $2820 \mathrm{~cm}^{-1}$ $3000 \mathrm{~cm}^{-1}$, are also seen due to aliphatic $\mathrm{v}(\mathrm{C}-\mathrm{H})$ group frequencies. The nickel and copper poly chelates also show weak to medium intensity bands within $3100-2900 \mathrm{~cm}^{-1}$ and at 3200 $2500 \mathrm{~cm}^{-1}$ due to aromatic and aliphatic $\mathrm{v}(\mathrm{C}-\mathrm{H})$ stretching vibrations. The broad signals of nickel complex (PMBFPRNi), were observed at $3250 \mathrm{~cm}^{-1}, 3325 \mathrm{~cm}^{-1}$ and at $3260 \mathrm{~cm}^{-1}$, followed by a sharp peaks at 3400,3490 and $3400 \mathrm{~cm}^{-1}$, due to hydrogen bonded and coordination or aggregation of water molecule to the metal ion, whereas the similar band disappears for the copper complex that is for (PMBFPRCu), respectively and may be due to coordination in copper poly chelate. (PMBFPRCu), poly chelate showed medium intensity bands within 3000-2800 $\mathrm{cm}^{-1}$, due to symmetrical and asymmetrical $v(\mathrm{C}-\mathrm{H})$ stretching vibrations of $\mathrm{CH}_{2}$ group. A medium intensity peak is observed at $2905 \mathrm{~cm}^{-1}$ for (PMBFPRNi) complex and is due to $\mathrm{v}(\mathrm{C}-\mathrm{H})$ aliphatic group frequencies. The copper poly chelate show a medium intensity bands within $3000-2800 \mathrm{~cm}^{-1}$ and are attributed to symmetrical and asymmetrical $v(\mathrm{C}-\mathrm{H})$ stretching of $\mathrm{CH}_{2}$ group. A strong band within $1620-1630 \mathrm{~cm}^{-1}$ corresponding to hydrogen bonded $v(\mathrm{C}=\mathrm{N})$ vibration is observed for the Ligand (PMBFPR) and is a confirmatory peak for the synthesized polymers. The copper poly chelate, (PMBFPRCu) showed a sharp intense peak at $1612 \mathrm{~cm}^{-1}$ of hydrogen bonded $\mathrm{v}(\mathrm{C}=\mathrm{N})$ azomethine stretch and was shifted to lower frequencies as compared to their respective ligand, attributed to charge transfer from furyl -Oto $\mathrm{Cu}$ (II) ion and due to coordination with metal ion. The nickel poly chelate (PMBFPRNi), showed strong absorption bands of hydrogen bonded $\mathrm{v}(\mathrm{C}=\mathrm{N})$ azomethine stretch at $1610 \mathrm{~cm}^{-1}$, the peak is shifted to lower frequency as compared to its ligand and may be due to coordination of furyl -O- with metal ion.

Electronic spectra: The UV/visible spectra of monomer $(\mathrm{MBF})$, ligand and polymetal complexes were recorded in DMF (Table-2). The spectra's were recorded in the range 190$700 \mathrm{~nm}$ (Fig. 3a). The spectra of monomer and ligand indicated three bands within $232-350 \mathrm{~nm}$ due to $\pi-\pi^{*}$ transitions within furyl rings and conjugated $\mathrm{C}=\mathrm{O}$ groups within aromatic ring systems. The ligand (PMBFPR) indicated the fourth band, due to $\pi-\pi^{*}$ transitions with in aromatic furyl rings and conjugated azomethine due to polycondensation and confirms its formation. The molecular weights of newly synthesized ligand and poly metal complexes were unknown therefore their $1 \%$ absorptivity was calculated. The poly chelate (PMBFPRCu)

\begin{tabular}{|c|c|c|c|}
\hline \multicolumn{4}{|c|}{$\begin{array}{c}\text { TABLE-2 } \\
\text { RESULTS OF SPECTROPHOTOMETRIC } \\
\text { STUDIES IN DMF AS SOLVENT }\end{array}$} \\
\hline S. No. & Compound & $\lambda(\mathrm{nm})$ & $\varepsilon \mathrm{Lmol}^{-1} \mathrm{~cm}^{-3}$ \\
\hline \multirow[t]{4}{*}{1.} & MBF & 235 & 12863 \\
\hline & & 288 & 8065 \\
\hline & & 350 & 5451 \\
\hline & Compound & $\lambda \mathrm{nm}(\varepsilon 1 \%)$ & \\
\hline \multirow[t]{4}{*}{2.} & PMBFPR & $238(272)$ & \\
\hline & & $285(228)$ & \\
\hline & & 357 (80) & \\
\hline & & $400(68)$ & \\
\hline \multirow[t]{4}{*}{3.} & PMBFPRCu & 240 (229) & \\
\hline & & $280(183)$ & \\
\hline & & 365 (183) & \\
\hline & & 425 (137) & \\
\hline \multirow[t]{4}{*}{4.} & PMBFPRNi & 245 (269) & \\
\hline & & $300(255)$ & \\
\hline & & $380(228)$ & \\
\hline & & $465(225)$ & \\
\hline
\end{tabular}
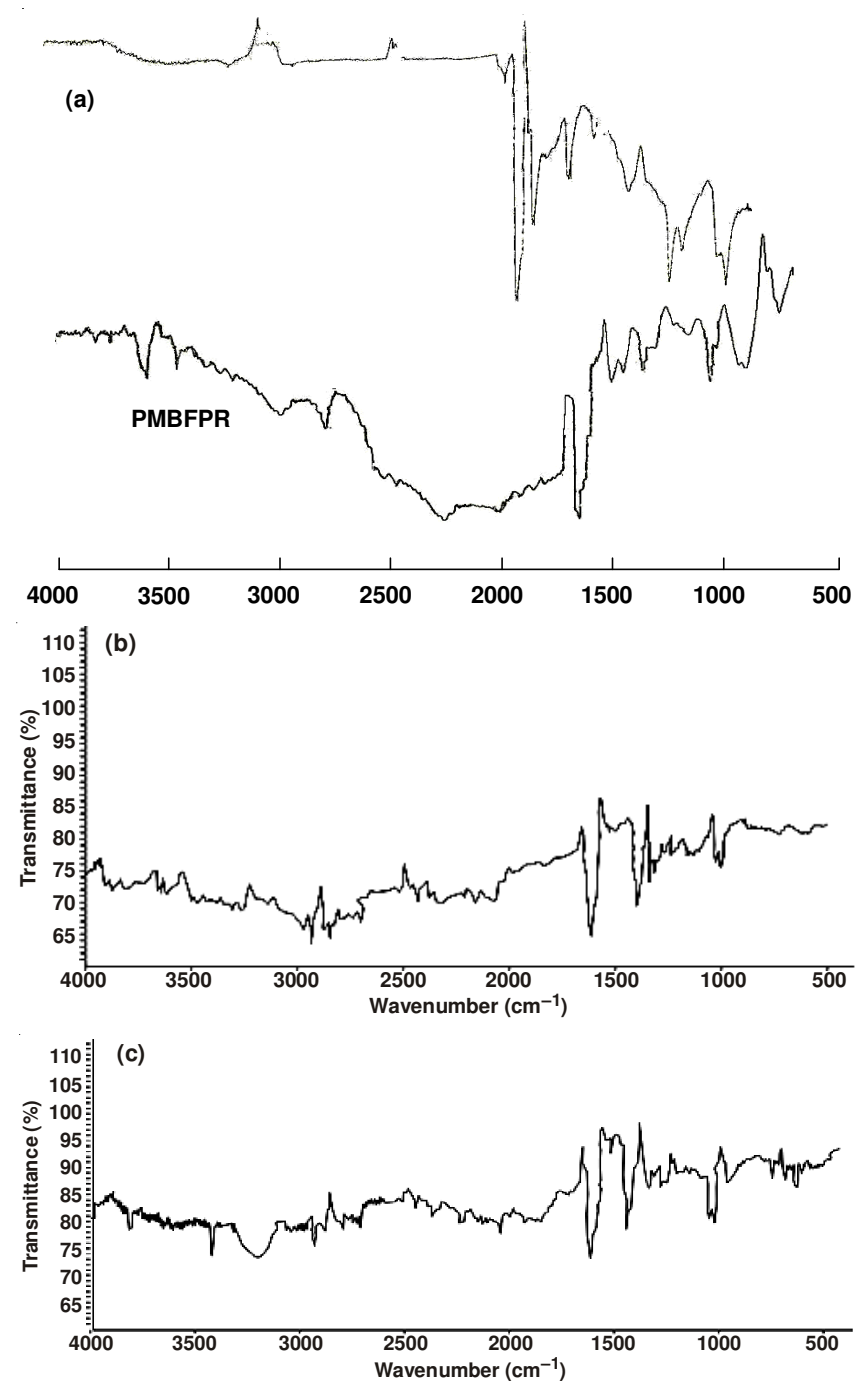

Fig. 2. (a, b, c,) FTIR Spectra of (MBF), (PMBFPR), (PMBFPRCu) and (PMBFPRNi), respectively 
indicated bands within 240-425 nm with $1 \%$ absorptivity ( $\varepsilon 1 \%=229-137.6 \mathrm{~L} \mathrm{~g} \mathrm{~g}^{-1} \mathrm{~cm}^{-1}$ ) the bands may be due due to $\pi-\pi^{*}$ transitions in hetero aromatic rings (Fig. 3b). The increase and shift in spectral band position towards longer wavelengths (lower frequencies) of (PMBFPRCu) as compared to (PMBFPR) is may be due to coordination with metal. The nickel (11) poly chelate (PMBFPRN)I indicated bands within 245-465 nm, with $1 \%$ absorptivity, ( $\varepsilon 1 \%=269.37-225.73$ $\mathrm{L} \mathrm{g}^{-1} \mathrm{~cm}^{-1}$ ), the poly metal chelates (PMBFPRNi) showed an increase in spectral band positions towards longer wavelengths (lower frequencies) as compared to copper(II) complex, is may be due to improved or better coordination sites with metal ions.
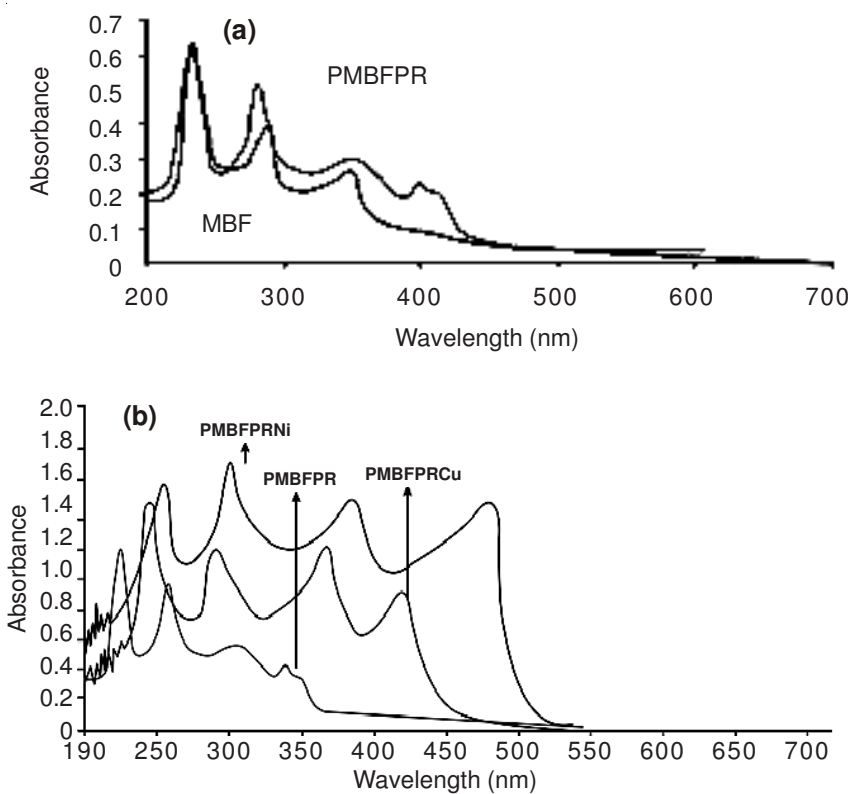

Fig. 3. (a) UV/visible spectra of (MBF), (PMBFPR); (b) UV/visible spectra of (PMBFPRCu), (PMBFPRNi)

Solubility of monomer, ligands and polymetal complexes: The monomer, polymer and poly metal complexes showed poor solubility in most of organic solvents.

Thermal analysis: The thermal analysis of monomer is shown in the figure the TG indicated initial weight loss of about $1.8 \%$ in the region $50-100{ }^{\circ} \mathrm{C}$ is due to moisture absorbed by the sample, between $250-400{ }^{\circ} \mathrm{C}$ the material suffered rapid weight loss. The loss rate was $0.3-\% /{ }^{\circ} \mathrm{C}$ at 388 ${ }^{\circ} \mathrm{C}$ which is the temperature of maximum rate of weight loss $\left(\mathrm{T}_{\max }\right)$. The DTA indicated a well-defined endothermic peak at $330{ }^{\circ} \mathrm{C}$. The peak is associated to the melting of monomer (Fig. 4a).

The results of thermogravimetric analysis indicated that for polymers (PMBFPR) loss in weight started at $220^{\circ} \mathrm{C}$ and loss of $32 \%$ absorbed up to $500{ }^{\circ} \mathrm{C}$ (Fig. 4b). The DTA indicated that the polymer (PMBFPR) indicated a well-defined endothermic peak at $400{ }^{\circ} \mathrm{C}$ which may be associated to the melting of the polymer. The TGA/DTA of poly metal chelate (PMBFPRCu) was shown in figure, the initial decomposition temperature IDT, of poly metal chelate was observed at $240{ }^{\circ} \mathrm{C}$ with a $2 \%$ weight loss followed by secondary weight loss of $15 \%$ at $330{ }^{\circ} \mathrm{C}$ (Fig. $4 \mathrm{c}$ ). Between $335^{\circ} \mathrm{C}$ and $360{ }^{\circ} \mathrm{C}$ the material suffered rapid weight loss the loss rate was $0.3 \% /{ }^{\circ} \mathrm{C}$ at $340{ }^{\circ} \mathrm{C}$ which is the temperature of maximum rate of weight loss $\left(\mathrm{T}_{\max }\right)$. A well-defined endothermic peak was observed at $390{ }^{\circ} \mathrm{C}$ and was may be due to the melting of poly chelate. The TGA/DTA of poly metal chelate (PMBFPRNi) was shown in figure, the weight loss was observed in two stages, the IDT initial decomposition temperature was observed at $249^{\circ} \mathrm{C}$ with a $10 \%$ weight loss, followed by secondary weight loss of 62 $\%$ at $385^{\circ} \mathrm{C}$. Between $330^{\circ} \mathrm{C}$ and $430{ }^{\circ} \mathrm{C}$ the material suffered rapid weight loss the loss rate was $0.4 \% /{ }^{\circ} \mathrm{C}$ at $400{ }^{\circ} \mathrm{C}$, which is the temperature of maximum rate of weight loss $\left(\mathrm{T}_{\max }\right)$. The DTA endothermic peak was observed at $422^{\circ} \mathrm{C}$ corresponding to melting of poly metal chelate (Fig. 4d). The TGA/DTA of all the investigated compounds reveals that the polymer metal complexes were found to be more thermally stable as compared to their parent compounds.

Viscometric analysis: Viscometric measurements are useful for characterizing the properties of the polymers and polymer metal complexes. The reduced viscosity $\left(\eta_{\text {red }}\right)$ for monomer was observed within $0.38-0.2 \mathrm{dl} / \mathrm{g}$ as compared to the polymer (PMBFPR) within $0.54-0.35 \mathrm{~d} 1 / \mathrm{g}$. The monomer (MBF) indicated $\eta$ within $0.378-0.237 \mathrm{dl} / \mathrm{g}$ as compared to
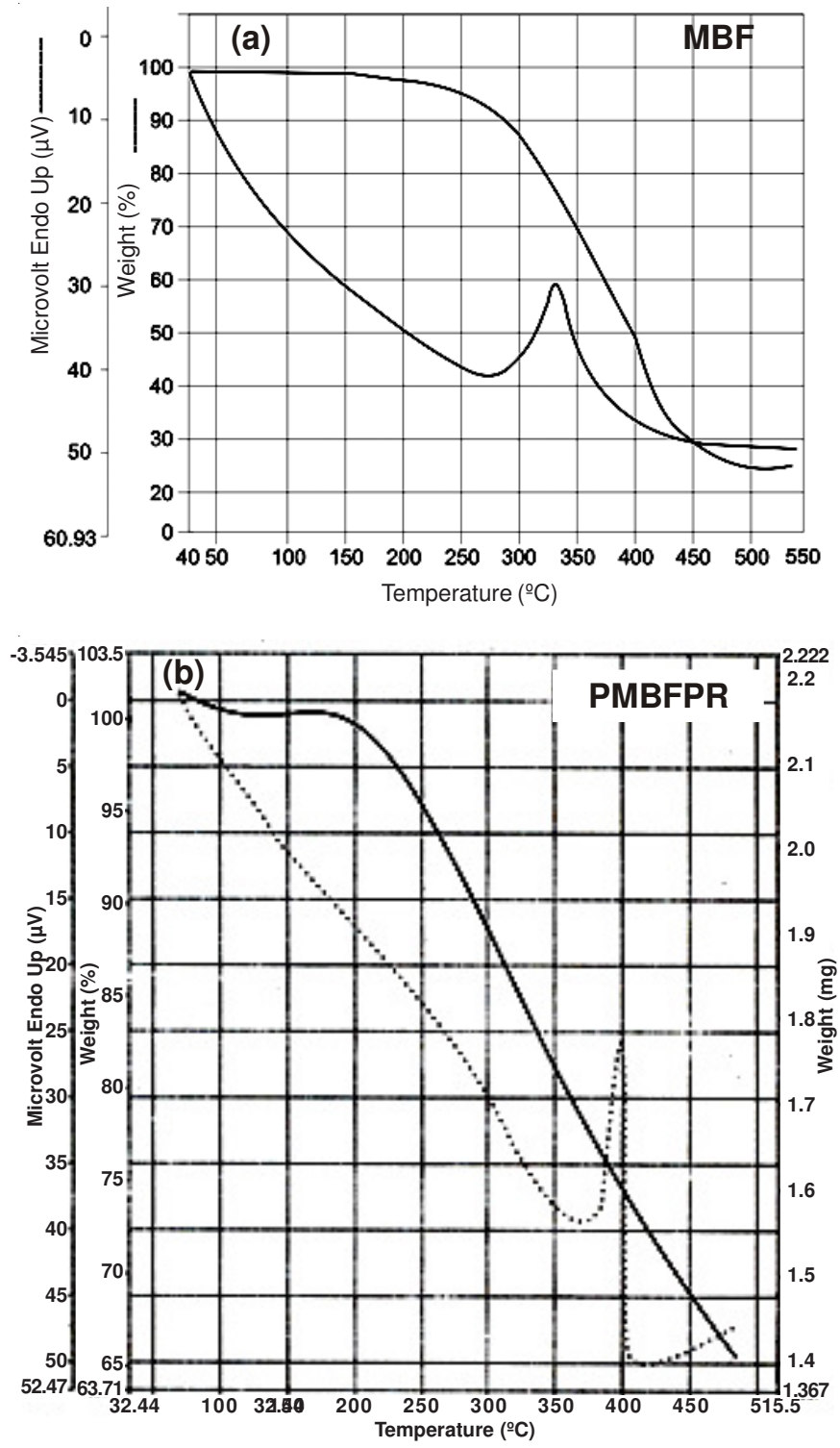

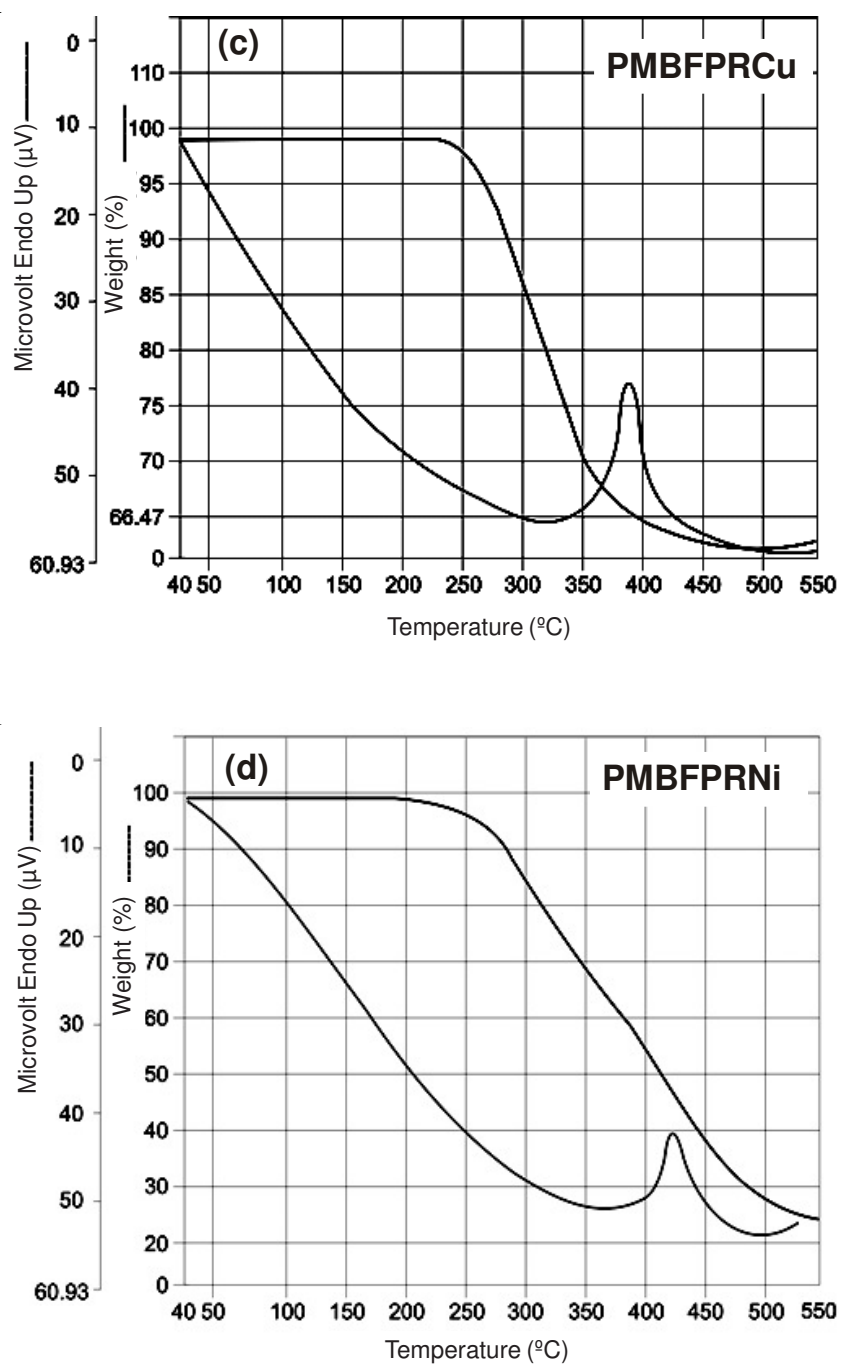

Fig. 4. (a) TGA/DTA of (MBF); (b) TGA/DTA of (PMBFPR); (c) TGA/ DTA of (PMBFPRCu); (d) TGA/DTA of (PMBFPRNi)

the polymers (PMBFPR), within 0.458-0.379 dl/g, respectively. The polymer indicated higher values of $\eta$ and supported the polymerization of the monomer. The reduced viscosity $\left(\eta_{\text {red }}\right)$ for poly metal chelate (PMBFPRCu) it is $0.4624-0.4001 \mathrm{dl} / \mathrm{g}$ and for (PMBFPRNi) poly metal complex it was 0.4619$0.3994 \mathrm{dl} / \mathrm{g}$. The relationship between $\left(\eta_{\text {red }}\right)$ and the concentration was lined i.e. linear, hence satisfying the Huggins equation. The values of $\left(\eta_{\text {red }}\right)$ showed increase with increase in concentration, due to the rise of intermolecular forces of attraction between the molecules and decrease with increase in temperature, due to the rise of vibrational frequency of molecules as on high temperatures the mobility among the molecules increases, with the result the internal confrontation or resistance to the flow decreases, hence viscosity decreases. The intrinsic viscosity for poly metal complexes (PMBFPRCu), (PMBFPRNi), were calculated from Huggins equation, the equation describes that when a graph is plotted between reduced viscosity and concentration, intercept give intrinsic viscosity of solution (Table-3). Intrinsic viscosity increases with increase in molecular weight of poly chelate (Fig. 5a). The poly metal complex (PMBFPRCu) has the higher intrinsic viscosity as compared to (PMBFPRNi) poly metal complex. (PMBFPRCu) has 0.4581-0.3808 dl/g and (PMBFPRNi)
$0.4576-0.3778 \mathrm{dl} / \mathrm{g}$ respectively (Fig. $5 \mathrm{~b}$ ). The absolute viscosity $\left(\eta_{\text {abs }}\right)$ for monomer (MBF) $0.182-0.399 \mathrm{~m} \mathrm{~N} . S / \mathrm{m}^{2}$ and for the polymers (PMBFPR) was in the range $0.262-0.488 \mathrm{~m} . \mathrm{N} . \mathrm{s} / \mathrm{m}^{2}$ and for polymer metal complex (PMBFPRCu), 0.585-0.371 m.N.s $/ \mathrm{m}^{2}$ for and (PMBFPRNi), 0.594-0.3801 m.N.s $/ \mathrm{m}^{2}$. The higher values of polymetal complexes as compared to their respective ligand may attribute to coordination. The values of $\left(\eta_{\mathrm{abs}}\right)$ increased with concentration due to the increase in the density of solution and possible formation of the associates. A decrease in $\left(\eta_{\text {abs }}\right)$ with increase in temperature may be attributed to increase in volume and decrease in density. A decrease in associations among polymer molecules could also occur at higher temperatures. All thermodynamic parameters of monomer, polymer and polymetal complexes in dilute solutions of DMF were calculated.

TABLE-3

\begin{tabular}{|c|c|c|c|c|c|}
\hline \multicolumn{6}{|c|}{$\begin{array}{c}\text { TABLE-3 } \\
\text { INTRINSIC VISCOSITY VALUES OF MONOMER, } \\
\text { LIGANDS AND POLYMETAL CHELATES (dl/g) }\end{array}$} \\
\hline \multirow{2}{*}{ Compound } & \multicolumn{5}{|c|}{ Temperature (K) } \\
\hline & 283 & 293 & 303 & 313 & 323 \\
\hline $\mathrm{MBF}$ & 0.3787 & 0.3447 & 0.2962 & 0.2582 & 0.2375 \\
\hline PMBFPR & 0.4577 & 0.4458 & 0.4185 & 0.3991 & 0.3794 \\
\hline PMBFPRCu & 0.4581 & 0.4476 & 0.4203 & 0.4002 & 0.3808 \\
\hline PMBFPRNi & 0.4576 & 0.4465 & 0.4197 & 0.400 & 0.3778 \\
\hline
\end{tabular}
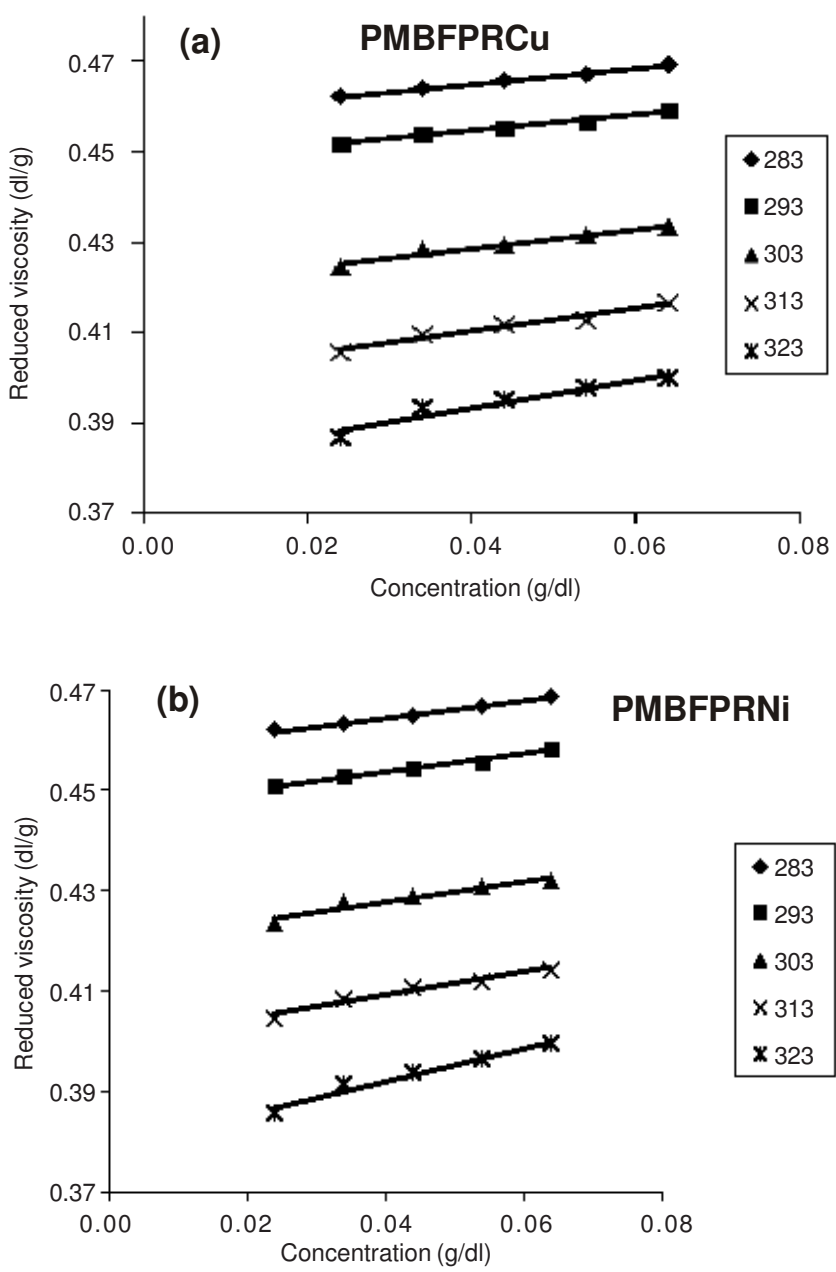

Fig. 5. (a) Graph Red VIS/conc. of (PMBFPRCu); (b) Graph Red VIS/ conc of (PMBFPRNi) 
The values of $\Delta \mathrm{G}_{\mathrm{V}}$ for $(\mathrm{MBF}) 13.978-14.094 \mathrm{~kJ} \mathrm{~mol}^{-1}$ as compared to the polymer (PMBFPR), 14.513-15.029, $\mathrm{kJ} \mathrm{mol}^{-1}$ and for poly metal chelate (PMBFPRCu) the values were 14.995-15.938 $\mathrm{KJ} \mathrm{mol}^{-1}$, for (PMBFPRNi) 15.031-16.002 KJ $\mathrm{mol}^{-1}$, for respectively. The values for the polymers increased with increase in temperature as well as concentration. An increase in $\Delta G_{v}$ with increase in the temperature indicates that shape transition of the polymer molecules takes place during flow process. The values of $\Delta \mathrm{H}_{\mathrm{v}}$ for (MBF) 14.302-14.525 kJ $\mathrm{mol}^{-1}$ higher than that of polymer (PMBFPR), 10.965-11.031, $\mathrm{KJ} \mathrm{mol}^{-1}$, whereas for poly metal complexes (PMBFPRCu) the values are 8.4694-8.4703 $\mathrm{KJ} \mathrm{mol}^{-1}$ for (PMBFPRNi) 8.3055-8.3088 $\mathrm{KJ} \mathrm{mol}^{-1}$ respectively. The lower values of $\Delta \mathrm{H}_{\mathrm{v}}$ were observed for polymer as compared to monomer (MBF), possibly, because of aggregation of the molecules in polymers and the same pattern was observed for poly metal chelates as compared to the ligand (PMBFPR), possibly, because of the increase in molecular weight in complexes, as increase in molecular mass need more energy, to overawe the flow of polymeric solvents. The values of $\Delta \mathrm{S}_{\mathrm{v}}$ for the monomer (MBF) was $-0.00069-0.00175 \mathrm{~J} / \mathrm{K}$ and for the ligand (PMBFPR), were $-0.0122-0.0127 \mathrm{~J} / \mathrm{K}$ whereas for polymetal complexes (PMBFPRCu)-0.023058-0.023119, for (PMBFPRNi) -0.022953$0.023817 \mathrm{KJ} \mathrm{mol}^{-1}$, The negative sign of $\Delta \mathrm{S}_{\mathrm{v}}$ for ligand as well as for poly metal complexes showed that during the flow molecules are becoming extended due to uncoiling of the polymer molecules in the solutions.

${ }^{1} \mathbf{H}$ NMR studies: The ${ }^{1} \mathrm{H}$ NMR spectrum of (MBF) indicated two multiplets at $\delta 9.81 \mathrm{ppm}$ and $\delta 9.603 \mathrm{ppm}$ due to aromatic $\mathrm{C}-\mathrm{H}$ protons, while these are absent in (PMBFPR) due to low solubility of the compound in DMF. The (MBF) showed a series of multiplets between $\delta 8.537$ ppm to $\delta 6.789$ ppm of furan ring confirming the aromatic nature of the compound, while the polymer (PMBFPR) contains three methylene groups at bridge position which could be assigned to two doublets at $\delta 3.358 \mathrm{ppm}$ corresponding to $-\mathrm{CH}_{2}$ and at $\delta 2.49$ ppm due to two $-\mathrm{CH}_{2}$ groups.

Biological studies: The antibacterial and antifungal studies of ligand (PMBFPR) and its complexes (PMBFPRCu) and (PMBFPRNi) were screened against Micrococcus flavus (G +ve), Staphylococcus aureus ( $\mathrm{G}+\mathrm{ve})$, Bacillus cirroflgellosus, Shigella flexneri (G+ve), Escherichia coli (G-ve) Candida albicans (G-ve), Aspergillus flavus (G-ve) and A. niger, by using agar well diffusion method. Tetracycline (an antibacterial) and miconazole (antifungal) were used as standard drugs. Platinum wire loop was used to apply the strains. Inoculation of the cultures of samples was accomplished, before pouring into the petri dishes. The wells with centers of $24 \mathrm{~mm}$ in diameter were dug in the media by using a germ-free or sterile cork borer. The concentrations suggested for making solutions of ligand and poly metal complexes was $1 \mathrm{mg} \mathrm{mL}^{-1}$ in DMF. The solutions of ligand and poly metal complexes were poured into the wells with the help of a micro pipette. The other wells were filled with DMF and reference antifungal and antibacterial drugs, serving as positive and negative controls respectively. The plates were incubated at once at $37^{\circ} \mathrm{C}$ for $24 \mathrm{~h}$. Antifungal and antibacterial activities were observed by measuring the diameter of zones in millimeters, presenting complete inhibition.
Tetracycline was used as standard drug for antibacterial activity and miconazole was used for antifungal activity. The ligand (PMBFPR) and its respective metal complexes showed individually the inhibitory effects against fungus and bacterial cultures. The ligand and complexes were screened against $M$. flavus, S. aureus, B. cirroflgellosus, S. flexneri, E. coli for antibacterial studies and C. albicans, A. flavus and A. Niger for antifungal studies. The results are summarized in Table-4a and $b$. The results revealed the facts that the newly synthesized ligand and its $\mathrm{Cu}$ (II) and $\mathrm{Ni}$ (II) complexes possess remarkable biological activity. The ligand (PMBFPR) showed (10, 15, 5, $15,10 \mathrm{~mm}$ ) zones of inhibition against the reported bacteria. The polymetal complex (PMBFPRCu) exhibited he highest antibacterial activity against $M$. flavus, S. aureus, B. cirroflgellosus, $S$. flexneri and E. coli. The complex (PMBFPRCu) exhibited $(24,15,10,20,24 \mathrm{~mm})$ and (PMBFPRNi) exhibit (15, 10, 5, $15,15 \mathrm{~mm})$, zones of inhibition against the reported bacteria.

\begin{tabular}{|c|c|c|c|c|c|}
\hline \multicolumn{6}{|c|}{$\begin{array}{c}\text { TABLE-4a } \\
\text { ANTIMICROBIAL ACTIVITY OF LIGANDS AND POLYMER } \\
\text { METAL COMPLEX (ANTIBACTERIAL) }\end{array}$} \\
\hline \multirow[b]{2}{*}{ Compound } & \multicolumn{5}{|c|}{ Zone of inhibition $(\mathrm{mm}) 50 \mu \mathrm{g} / \mathrm{mL}^{-1}$} \\
\hline & $\begin{array}{c}M . \\
\text { flavus }\end{array}$ & $\begin{array}{c}S . \\
\text { Aureus }\end{array}$ & $\begin{array}{c}B . \\
\text { cirrioflgellosus }\end{array}$ & $\begin{array}{c}S . \\
\text { flexneri }\end{array}$ & E. coli \\
\hline PMBFPR & + & ++ & - & ++ & + \\
\hline PMBFPRCu(II) & ++++ & ++ & + & +++ & ++++ \\
\hline PMBFPRNi(II) & ++ & + & - & ++ & ++ \\
\hline Tetracycline $^{\mathrm{a}}$ & - & + & - & + & ++ \\
\hline
\end{tabular}

\begin{tabular}{|c|c|c|c|}
\hline \multicolumn{4}{|c|}{$\begin{array}{c}\text { TABLE-4b } \\
\text { ANTIMICROBIAL ACTIVITY OF LIGANDS AND POLYMER } \\
\text { METAL COMPLEX (ANTIBACTERIAL) }\end{array}$} \\
\hline \multirow[t]{2}{*}{ Compound } & \multicolumn{3}{|c|}{ Zone of inhibition $(\mathrm{mm}) 50 \mu \mathrm{g} / \mathrm{mL}^{-1}$} \\
\hline & C. albicans & A. flavus & A. niger \\
\hline PMBFPR & ++ & + & ++ \\
\hline PMBFPRCu(II) & +++ & +++ & ++ \\
\hline PMBFPRNi(II) & ++ & + & ++ \\
\hline Miconazole $^{\mathrm{b}}$ & - & - & - \\
\hline
\end{tabular}

The ligand and complexes exhibit zones of inhibition against $C$. albicans, A. flavus and A. niger for their antifungal activity. The ligand (PMBFPR) showed (15, 10, $10 \mathrm{~mm})$, zones of inhibition against the reported fungi. The complex (PMBFPRCu) exhibited he highest antifungal activity and (20, 20, $15 \mathrm{~mm}$ ) and (PMBFPRNi), showed (15, 10,15 mm) zones of inhibition against the reported fungi. All the newly synthesized metal complexes showed appreciably promising antimicrobial activity against all the microorganisms and the zones of inhibition are evaluated in Tables-4[A],[B] respectively. An observable increase in antimicrobial activity of polymeric compounds was observed, when coordinated ${ }^{21}$. This improvement in biological activity could be justified on ground of possessing an azomethine $\mathrm{C}=\mathrm{N}$ bond. As polarity of metal ion is reduced due to chelation, or due to incomplete sharing or affecting only a part of its positive charge with the donators 
and due to movement of $\pi$ electrons in the chelate ring ${ }^{22,23}$ resulting, or favouring perforation from one side to other of the bacterial wall of the bacterium or protozoan, thus increasing the lipophilic nature of the compound and destroying them more effectively.

\section{Conclusion}

The newly synthesized monomer (MBF) was condensed with a 1,3-propylenediamine in $(1: 1)$ molar ratio to yield a Schiff base polymer ligand poly(4,4'-methylene- bis(furfural-dehyde)-1,3-propylenediimine (PMBFPR). The synthesized poly metal complexes were prepared in equimolar ratio (1:1) of ligand and metal salts. The poly metal complexes were achieved in assessable yields by the interaction of copper(II) and nickel(II) salts with the Schiff based ligands in DMF. The synthesized poly metal complexes were non-hygroscopic and stable at room temperature. They were thoroughly characterized by CHN, spectral (FT-IR, UV-VIS, ) analysis. UV-VIS spectra of ligand and polymetal complexes showed substantial bathochromic shifts, approving the formation of complexes. The biological studies of ligand and complexes revealed that they possesses significant antibacterial and antifungal properties, against all the fungal and bacterial strains and the data revealed that coordination increased the antimicrobial activity. All the compounds showed poor solubility in organic solvents. The intrinsic viscosity for poly metal complexes PMBFPRCu, PMBFPRNi, was calculated from Huggins equation. On the grounds of substantial thermal stability and promising antimicrobial activity of these polymer metal complexes, they can be used as antifungals and for various healthful applications, requiring thermal decontamination.

\section{ACKNOWLEDGEMENTS}

The authors expressed their sincere thanks to Institute of Advance Research Studies in Chemical Sciences and Dr. M.A. Kazi Institute of Chemistry, for using all the instrumental techniques and the provision of necessary facilities.

\section{REFERENCES}

1. I.A. Kamal and A.A Khalaf, J. Appl. Polym. Sci., 77, 1218 (2000).

2. O. Catanescu, M. Grigoras, G. Cololin, A. Dobreanu, N. Hurduc and C.I. Simionescu, Eur. Polym. J., 37, 2213 (2001).

3. M. Grigoras, C.O. Catenescu and G. Colotin, Macromol. Chem. Phys., 202, 2262 (2001).

4. X. Luo, X. Wang, S. Wu and Y. Liang, J. Collid. Interf. Sci., 258, 432 (2003).

5. S. Destri, M. Pasini, C. Pelizzi, W. Porzio, G. Pridieri and C. Vignali, Macromolecules, 32, 353 (1999).

6. M. Cazacu, M. Marcu, A. Vlad, A. Toth and C. Racles, J. Polym. Sci. Part A, Polym. Chem., 41, 3169 (2003).

7. K. Naka, A. Azuma and Y. Chujo, Macromol. Rapid. Commun., 19, 523 (1998).

8. M.Y. Khuhawar, A.H. Channar and S.W. Shah, Eur. Polym. J., 34, 133 (1998).

9. M.Y. Khuhawar, M.A. Mughal and A.H. Channar, Eur. Polym. J., 40, 805 (2004).

10. M.Y. Khuhawar, A. Shah and M.A. Mughal, Chin. J. Polym. Sci., 25, 399 (2007).

11. S. Banerjee, C. Saxena and P.K. Gutch, Eur. Polym. J., 32, 661 (1996).

12. P.K. Gutch, S. Banerjee, D.C. Gupta and D.K. Jaiswal, J. Polym. Sci. Polym. Chem. Ed., 39, 383 (2001).

13. M.R. Maurya, A. Kumar, P. Manikandan and S. Chand, Appl. Catal. A, 277, 45 (2004).

14. R. Grunes and W. Sawondy, J. Chromatogr., 322, 63 (1985).

15. W. Li and M. Wan, J. Appl. Polym. Sci., 62, 941 (1996).

16. D.H. Sutaria, J.R. Patel and M.N. Patel, J. Indian Chem. Soc., 73, 309 (1996).

17. C.S. Marvell and N. Torkoy, J. Am. Chem. Soc., 79, 6000 (1957).

18. M.R. Filipovic, K. Duerr, M. Mojovic, V. Simeunovic, R. Zimmermann, V. Niketic and I. Ivanovic-Burmazovic, Angew. Chem. Int. Ed., 47, 8735 (2008).

19. K.I. Vilayetoglu and A.R. Topak, J. Appl. Polym. Sci., 85, 2002 (2004).

20. K.I. Demir and H.O. Vilayetoglu, Synth. Met., 126, 183 (2002).

21. R. Olar, M. Baded, E. Cristiana, V. Lazar, R. Cernat and C. Balotescu, J. Thermal. Anal. Calorim., 80, 451 (2005).

22. C.M. Sharaby, Spectrochim. Acta A, 66, 1271 (2007).

23. H.L. Singh, S. Varshney and A.K. Varshney, Appl. Organomet.Chem., 14, 212 (2000). 